\title{
The first whipspider (Arachnida: Amblypygi) and three new whipscorpions (Arachnida: Thelyphonida) from the Lower Cretaceous Crato Formation of Brazil
}

\author{
Jason A. Dunlop and David M. Martill
}

\begin{abstract}
The first whipspider (Arachnida: Amblypygi) and three new examples of whipscorpions (Arachnida: Uropygi: Thelyphonida) are described from Lower Cretaceous (Aptian) strata of the Crato Formation, Ceará State, Brazil. The whipspider is described as Britopygus weygoldti gen. et sp. nov. It resembles members of the extant family Charinidae, but cannot be unequivocally placed. Two of the whipscorpions are referred to Mesoproctus rowlandi Dunlop, 1998 and one could be a subadult, since, like juveniles of extant species, it has a relatively broad anterior sternum. There are differences between these two specimens in pedipalp and flagellum morphology, but both characters are variable within extant species. The third and largest whipscorpion is incomplete and referred to Mesoproctus sp. Its carapace length is equal to or exceeds that of the largest known extant genus Mastigoproctus Pocock, 1894.
\end{abstract}

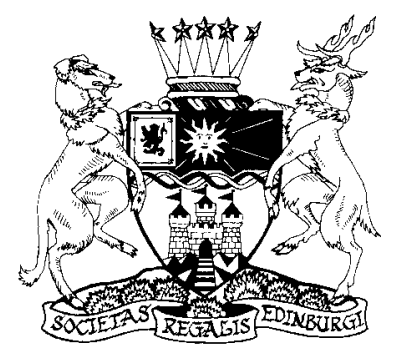

KEY WORDS: Aptian, Arthropoda, Ceará State, Chelicerata

Fossil arachnids are extremely rare in rocks of Mesozoic age. The arachnofauna from the Lower Cretaceous (Aptian) Crato Formation of Ceará State, Brazil is therefore a significant addition to their fossil record. In contrast to insects (e.g. Grimaldi 1990), relatively few arachnids from this locality have been described, probably because arachnids are naturally rarer than insects and less likely to become preserved by, for example, flying into water. The described arachnids include provisional accounts of spiders (Araneae) (Campos et al. 1988), one of which was described as Cretaraneus martinsnetoi Mesquita, 1996, and a scorpion (Scorpiones), Araripescorpius ligabuei Campos, 1986. There are also descriptions of a camel spider (Solifugae), Cratosolpuga wunderlichi Selden, 1996 (in Selden \& Shear 1996) and a whipscorpion (Uropygi: Thelyphonida), Mesoproctus rowlandi Dunlop, 1998. Fossil eggs have been discovered on bird feathers which could be evidence for mites (Acari) (Martill \& Davis 1998) and we are aware of an undescribed specimen which could also be a Crato Formation mite. Additional arachnid material from the Crato Formation awaits description.

Whipspiders (Amblypygi) and whipscorpions are two distinctive, closely related groups of arachnids characterised by subraptorial pedipalps (they were originally united under a single order, Pedipalpi), and a slender first pair of legs; see Shultz (1990, 1993, 1999) for apomorphies of Amblypygi, Uropygi and the Pedipalpi clade they form together. Whipspiders have a rounded prosoma, highly spinose pedipalps and very slender legs (see Weygoldt (2000) for a summary of their biology). By contrast, whipscorpions have a more elongate prosoma, more robust pedipalps and an elongate opisthosoma which ends in a long 'whip' or flagellum. Fossils of both groups have also been recorded from the Carboniferous (see Petrunkevitch (1953), Brauckmann \& Koch (1983) and Dunlop \& Horrocks (1996) for reviews) and fossil amblypygids have been described from Tertiary ambers (Schwaller 1982).

Here we describe the first whipspider from the Mesozoic plus three new examples of Crato Formation whipscorpions. The two smaller whipscorpions are recognised as further examples of the previously described species Mesoproctus rowlandi. Both are better preserved than Dunlop's (1998) holotype and include details of the ventral surface, claws on the legs and the distinctive posterior flagellum. The largest whipscorpion is referred simply to Mesoproctus sp. It is incomplete, but enormous; at least as big as, if not bigger than, the largest living whipscorpions ever recorded.

\section{Materials and methods}

The whipspider and one of the whipscorpions are deposited in the Staatliches Museum für Naturkunde in Stuttgart (respectively SMNS 64332 and 64331). The best-preserved whipscorpion and the largest whipscorpion are both deposited in the palaeontology collections of the Museum für Naturkunde, Berlin (respectively MB.A. 975 and 1041). Specimens were prepared using a dissecting needle to gently remove pieces of the relatively soft matrix obscuring details of the body. The specimens were drawn using a camera lucida and compared to extant whipspider and whipscorpion material in the zoological collections of the Museum für Naturkunde, Berlin. Morphological terminology mostly follows Shultz $(1993,1999)$ for extant taxa. Measurements in the descriptions are given in $\mathrm{mm}$.

\subsection{Geology, stratigraphy and palaeoenvironment}

The fossils described here have been obtained from the Nova Olinda Member of the Crato Formation of southern Ceará, NE Brazil. The Nova Olinda Member is a finely laminated limestone Konservat-Lagerstätte dated as Aptian (Early Cretaceous) on the basis of palynological evidence (Pons et al. 1990). It lies at the base of the Crato Formation which is a more than $30 \mathrm{~m}$ series of laminated limestones, silty clays, silts and sands in which the basal Nova Olinda Member reaches up to $12 \mathrm{~m}$ in thickness and extends over much of the eastern part of the Araripe Basin. This deposit has become famous for its abundant, diverse and very well preserved entomofauna and vertebrate fossils (Martill 1993). 

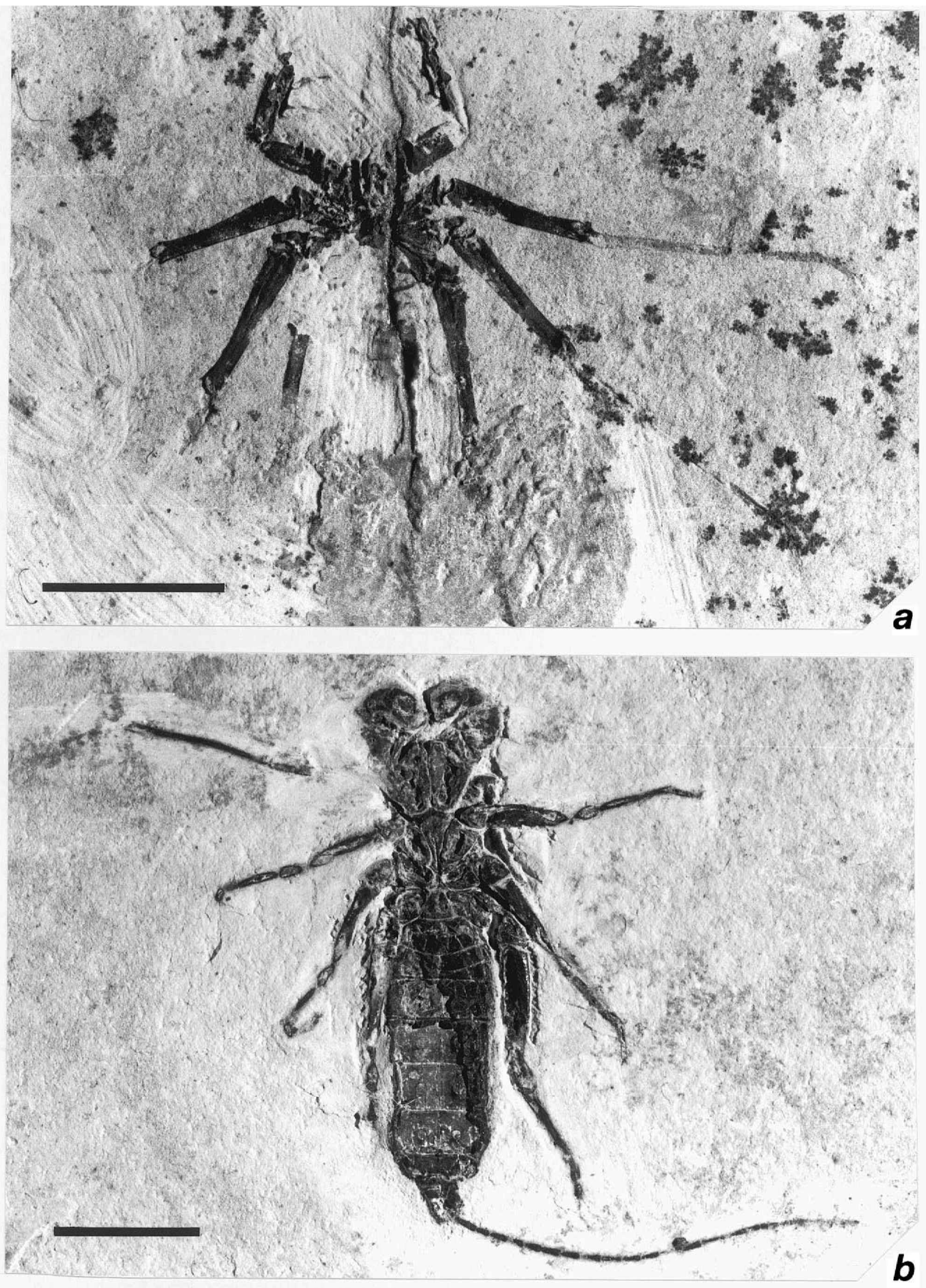

Figure 1 (a) Britopygus weygoldtigen. et sp. nov. SMNS 64332; an incomplete whipspider (Amblypygi) in ventral view; opisthosoma and antenniform first pair of legs not preserved; (b) Mesoproctus rowlandi Dunlop, 1998. MB.A. 975; a well-preserved fossil whipscorpion (Thelyphonida) showing primarily the ventral surface with the opisthosoma broken to reveal some of the dorsal surface. Both from the Lower Cretaceous (Aptian) Crato Formation of Brazil; scale bars represent $5 \mathrm{~mm}$. 

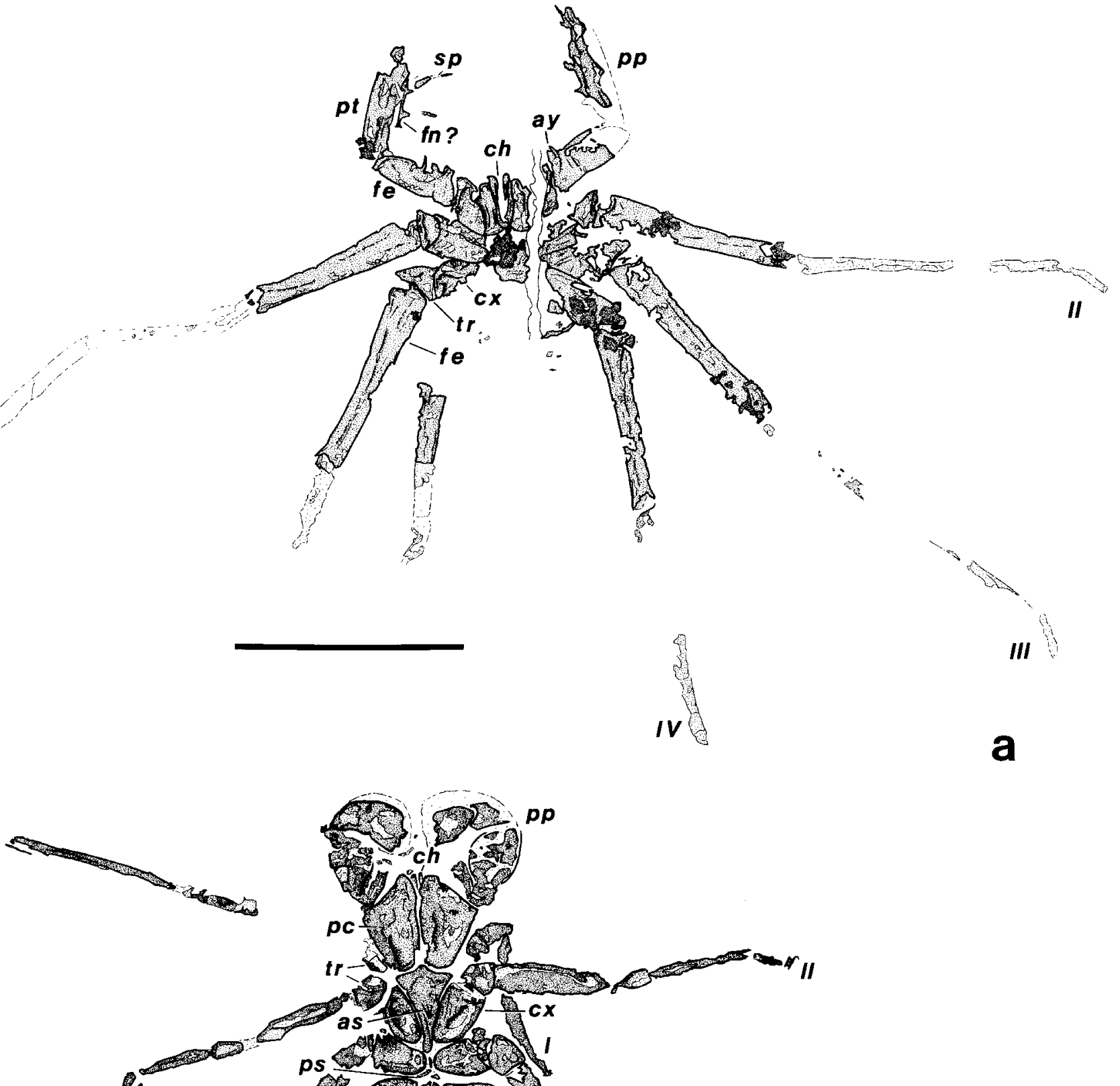

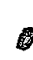


This highly fossiliferous member yields abundant fishes (Davies \& Martill 1999), rarer pterosaurs (Martill \& Frey 1998) and other tetrapods (Martill \& Filguera 1994; Martill \& Frey 1995), insects (Grimaldi 1990), arachnids (this paper) and diverse plants (Maisey 1991). It is mined extensively between the towns of Nova Olinda, Santana do Cariri, and the village of Tatajuba in more than 100 small quarries (see Martill 1993 for locality details). The stone is worked by hand and, consequently, many fossils are discovered. Most fossils are obtained from the quarry workers and a thriving trade has developed, adding an important source of income for a very low-paid community. At nearly all exposures the limestone is deeply weathered and the non-mineralised skeleton fossils are preserved as reddish brown geothitic pseudomorphs after pyrite which replaces and coats cuticle. Voids within the fossils are usually filled with clear calcite.

The Nova Olinda Member was deposited in a saline lagoon that probably had anoxic bottom waters. A freshwater surface layer may have supported pelagic and planktonic invertebrates and small fishes, but the majority of fossils appear to be of autochthonous flying forms. Terrestrial invertebrates are very much rarer than flying forms. Benthic invertebrates such as molluscs are lacking. Most workers consider that the Nova Olinda Member lagoon was surrounded by a semi-arid hinterland dominated by xerophytic plants (Martill 1993; Maisey 1990). Portions of plants and even entire plants occur sporadically. Entire plants comprising leaves, stems and root masses are assumed to have drifted in from rivers, whereas fragments are thought to represent damaged material blown in during storms.

\subsection{Abbreviations}

The following abbreviations are used in the figures: ap = tergal muscle apodeme, as = anterior sternum, ay = possible ventral apophysis on trochanter, bs = basitarsus (or metatarsus), $\mathrm{ch}=$ chelicerae, $\mathrm{cl}=$ tarsal claws, $\mathrm{cx}=$ coxa, $\mathrm{fe}=$ femur, $\mathrm{fg}=$ flagellum, fn? = possible flange bearing spines on pedipalpal tibia, $\mathrm{ke}=$ interocular keel, $\mathrm{me}=$ median eyes, op $=$ opisthosomal opercula, $\mathrm{pc}=$ pedipalpal coxae, $\mathrm{pp}=$ pedipalp, $\mathrm{ps}=$ posterior sternum, $\mathrm{pt}=$ patella, $\mathrm{py}=$ pygidium, $\mathrm{sc}=$ possible sclerites in joint arthrodial membrane, $\mathrm{se}=$ setae, $\mathrm{sp}=$ spines on the pedipalp, st $=$ sternite, $\operatorname{tg}=$ tergite, $\mathrm{ti}=$ tibia, $\operatorname{tr}=$ trochanter, ts = tarsus, ? = unknown material probably of organic/inorganic origin overlying specimen. Legs numbered from I-IV.

\section{Morphological interpretation}

\subsection{The whipspider}

The fossil (SMNS 64332) is light brown in colour, but with some overlying darker patches (Figs 1a, 2a). A split runs through the fossil in an antero-posterior direction to the right of the midline, obscuring the morphology here. Its habitus, with its large, spinous pedipalps and slender legs, is typical for extant Amblypygi. The chelicerae are relatively well preserved and both include the movable finger, or fang, as a pointed structure which is folded back onto the basal podomere and tapers distally in a posterior direction close the ventral midline.

The pedipalps are partially complete, robust and orientated in a horizontal plane. In extant taxa the pedipalpal coxae usually cover more of the chelicerae in ventral view, implying that these coxae in the fossil have become laterally splayed, perhaps as a result of compaction. The trochanter of the pedipalp bears a projection which could be the ventral apophysis (sensu Weygoldt 1996) seen in some extant taxa such as Charinidae. The taxonomic significance of this structure is discussed in detail below. A pale area between the pedipalpal femur and patella on the left side of the fossil could be the remains of an arthrodial membrane between these podomeres. The large spines on the pedipalp - most clearly preserved on the left side of the fossil-do not appear to emerge from the main body of the podomere, being slightly separated from it by a thin piece of matrix The fossil is in ventral view, thus the spines may have been borne on a slight projection or flange emerging dorsally from the podomere, a structure seen in some extant taxa (see below).

The first leg, antenniform in extant taxa, is not preserved in the fossil, although its coxa appears to be present as a slender element behind the pedipalpal coxa on the left side. Legs IIIV are more complete, but podomeres distal to the femur are poorly preserved, typically forming impressions in the matrix which only show the structure in outline. By contrast the femora are generally well preserved and the slight threedimensionality in the fossil suggests that, as in extant amblypygids, the femora were rather flattened podomeres held with the prolateral face uppermost and thus operating in a mostly horizontal plane. This leg morphology and orientation allows extant representatives to sit flattened against the substrate and to crawl easily into narrow spaces.

\subsection{The whipscorpions}

2.2.1. MB.A 975. This fossil is an almost complete, probably juvenile specimen (see 2.3), the anterior half of which is preserved in ventral view, but the opisthosomal sternites of which have broken away to reveal the overlying tergites (Figs 1b, 2b). The whole specimen is dark brown against the matrix. As in extant Thelyphonida, the pedipalps are massive and are preserved folded in on themselves such that only the trochanter, femur and patella, are clearly preserved here. The pedipalpal coxae are also massive and together they form a large, fused structure below the mouthparts, the camerostome, which in both this fossil and Recent forms has a pair of median processes or endites. A small pair of medial structures above and between these processes probably represents the chelicerae.

The large, so-called anterior sternum forms a ' $\mathrm{Y}$ '-shaped plate between the second pair of leg coxa. The corresponding posterior sternum is not clearly preserved, but may be represented in this fossil by a series of small sclerites between the third coxae. The legs themselves are relatively complete, although preservation tends to deteriorate distally and none show the characteristic division of the telotarsus into tarsomeres seen in extant species. The legs are mostly preserved flattened with the prolateral face uppermost (see also comments on the amblypygid legs in 2.1) and a pair of claws, or ungules, is preserved at the end of at least two of the legs. Remarkably, leg IV on the right side includes what appears to be an impression of the arthrodial membrane between the trochanter and femur, complete with tiny sclerites in the membrane, elements which also occur in living whipscorpions.

Anteriorly the opisthosoma begins with the triangular first sternite lying between the coxae of leg IV. Studies of Recent taxa (Shultz 1993) have shown that the next two plates in thelyphonids are not true sternites, but lung-bearing opercula. In both this fossil and extant forms, the anterior operculum is a large, posteriorly rounded plate. The corresponding posterior operculum is somewhat smaller. Posterior to this, the ventral surface of the specimen has broken and reveals increasingly more of the underlying tergites. The ventral surface has clearly been compressed onto the dorsal surface which is relatively undistorted. Tergites $6-8$ are particularly well preserved and include paired, circular apodomes midway along the length of the tergite either side of a clearly demarcated midline. Opisthosomal soft tissues are not preserved. The pygidium is well 
preserved, as is the flagellum which comprises a series of individual articles.

2.2.2. SMNS 64331. This is another almost complete, but less well-preserved specimen, also in ventral view (Figs 3a, 4a). The specimen is quite pale, darker on the limbs and flagellum. As in MB.A 975 the pedipalps and their coxae are large, but in outline the pedipalps of SMNS 64331 appear slightly less robust. The sternal region is not clearly preserved, but the leg coxae are quite well defined on the left side. In comparison to extant forms, the leg 1 coxa is probably the small element marked in Fig. 4a. The ill-defined, subtriangular area immediately posterior to this appears too large to be the coxa (compare with the better-preserved Fig. 2b) and the coxae of legs II-IV are more clearly visible. The subdivision of the leg 1 telotarsus into the characteristic antenniform distal region is not apparent. Structures at the tip of the tarsus here are suggestive of a pair of claws, but this may be taphonomic since leg I lacks claws in all extant forms; a synapomorphy of the Pedipalpi clade (Shultz 1999). Again, the legs are preserved with the prolateral face uppermost; in this case the retrolateral face is seen in this ventral view, and comparisons with extant whipscorpions suggest this is probably similar to the life position. Short spines or setae are clearly preserved towards the distal end of limb III on the ventral face of the tibia and tarsal region. Comparable spination occurs here in extant taxa. The flagellum is well preserved and narrows distally, but in contrast to MB.A 975 the individual articles are approximately as long as broad (compare with Fig. 2b).

2.2.3. MB.A. 1041. This specimen is a very large prosoma in dorsal view with almost complete pedipalps, but poorly preserved legs (Figs. 3b, 4b). The specimen is brown in colour, but lighter on the pedipalps. The fossil preserves some raised, antero-ventral lineations posterior to the median eyes. This is followed by a raised, narrow, posterior-curving, ridge-like structure preserved behind these lineations, and by a raised, elongate 'V'-shaped structure (Fig. 4b: ?). Nothing comparable to this is recorded in extant taxa and so this structure could be of taphonomic origin.

MB.A. 1041 is a very large whipscorpion. The largest living whipscorpions are Mastigoproctus giganteus (Lucas, 1835) and Mastigoproctus maximus (Tarnani, 1889). Mastigoproctus Pocock, 1894 has a New World distribution (e.g. Rowland \& Cooke 1973) which includes Brazil, where the Crato Formation was deposited. Extant specimens of the larger species of Mastigoproctus have been recorded with carapace lengths of $28.0 \mathrm{~mm}$ (Mello-Leitao 1931) and $29 \cdot 8 \mathrm{~mm}$ (Mark Rowland, pers. comm.). In fact, within M. giganteus the larger forms seem to come from Mexico, as opposed to the southern USA, and larger size might correlate with a longer foraging period (Justin Schmidt, pers. comm.). With a carapace length of $32.5 \mathrm{~mm}$, our Cretaceous specimen is clearly of the same order of magnitude as large Mastigoproctus, and to the best of our knowledge our fossil represents the largest carapace ever recorded for whipscorpions. Since no other extant genus approaches this size, Mesoproctus and Mastigoproctus might be closely related taxa.

\subsection{Are the small whipscorpions juveniles?}

Dunlop's (1998) holotype of $M$. rowlandi was relatively poorly preserved, essentially showing the animal only in outline. Two of the new specimens described here (MB.A. 975 and SMNS 64331) match the overall size and proportions of the holotype of this species and are thus referred to $M$. rowlandi (see section 3). Our new fossils are considerably better preserved. MB.A. 975 (Fig. 1b, 2b) shows the gross morphology very clearly and both specimens include several new details, especially setae, the flagellum, muscle apodemes, sclerites between the trochanter-femur joint and claws at the ends of the legs (see also 2.2). All of these features are seen in living whipscorpions and support the hypothesis that essentially modernlooking Thelyphonida were present in the Cretaceous; and perhaps even in the Craboniferous (Dunlop \& Horrocks 1996).

The presence of a much larger whipscorpion (MB.A. 1041) in the Crato fauna raises questions about whether this is a new species, or simply a large, possibly adult form of $M$. rowlandi; the implication being that the smaller examples are juveniles. In support of this, there is evidence for MB.A. 975 being a juvenile. In their studies of two unrelated extant whipscorpions, both Yoshikura (1965) and Weygoldt (1971) noted that the shape and proportions of the anteriormost prosomal sternite changes slightly during ontogeny; specifically the anterior sternite is relatively wide in juveniles, becoming narrower and more elongate, especially where it tapers in the two anterior corners and posteriorly, as the animal matures (see Yoshikura 1865, figs 46-50). This sternite is clearly preserved in MB.A. 975 (Fig. 2d: as) and comparing it to both juveniles and adults of the extant species Mastigoproctus giganteus suggests that it is more similar to the juvenile example, having a relatively wide posterior half to the sclerite (Fig. 5).

\section{Systematic palaeontology}

\section{Order AMBLYPYGI Thorell, 1883 \\ Family uncertain}

Remarks. Weygoldt $(1996,2000)$ proposed the most recent synthesis of extant amblypygid higher systematics, recognising five families. Unfortunately this new fossil is known primarily from the ventral prosoma with incomplete appendages and does not preserve characters such as genitalia, cheliceral teeth and the presence or absence of a pulvillus at the ends of the legs. This makes it difficult to place the fossil in Weygoldt's scheme with confidence. The relatively well-developed spines on the femur of the pedipalp (Figs 1a, 2a) suggests that the fossil does not belong in Paracharonitidae, the most basal of the extant whipscorpions, and it lacks the elongate pedipalps with a characteristic distal 'hand' seen in the more derived family Phrynichidae. However, the pedipalps develop allometrically during ontogeny (Weygoldt 1995) and the small size of the fossil in comparison to many extant Amblypygi might indicate that it is a juvenile. Furthermore, since sexual dimorphism in pedipalp size is also known (e.g. Weygoldt 1972) it would be unwise to draw conclusions from the proportions of the pedipalp alone. In overall habitus, the fossil resembles certain small members of extant genera like Phrynus (Phrynidae) and Charinus (Charinidae), see for example illustrations of female charinids from Brazil described originally as charontids by Weygoldt (1972). However, it does not preserve unequivocal autapomorphies of either family.

Phrynidae are, like this fossil, a New World group which have a spine, as opposed to an apophysis, on the trochanter. Smaller phrynid species such as members of Phrynus (formally Tarantula) tend to have a fairly robust pedipalpal patellae with the large spines borne on a dorsal flange (pers. obs.), a feature which could be present in the fossil (Fig. 2a: fn?). Alternatively, extant Charinidae have a circumtropical distribution and are characterised by both an apophysis on the trochanter (Weygoldt 1996, pers. comm.), a feature which appears to be present in this fossil (Fig. 2a: ay), and a large patella spine - a tibial spine in some terminologies - on the pedipalp (Fig. 2a: $\mathrm{sp}$ ), a structure which again originates on a flange in extant charinids (P. Weygoldt, pers. comm.). Our specimen may therefore be either a phrynid or, more likely, a charinid, but we 

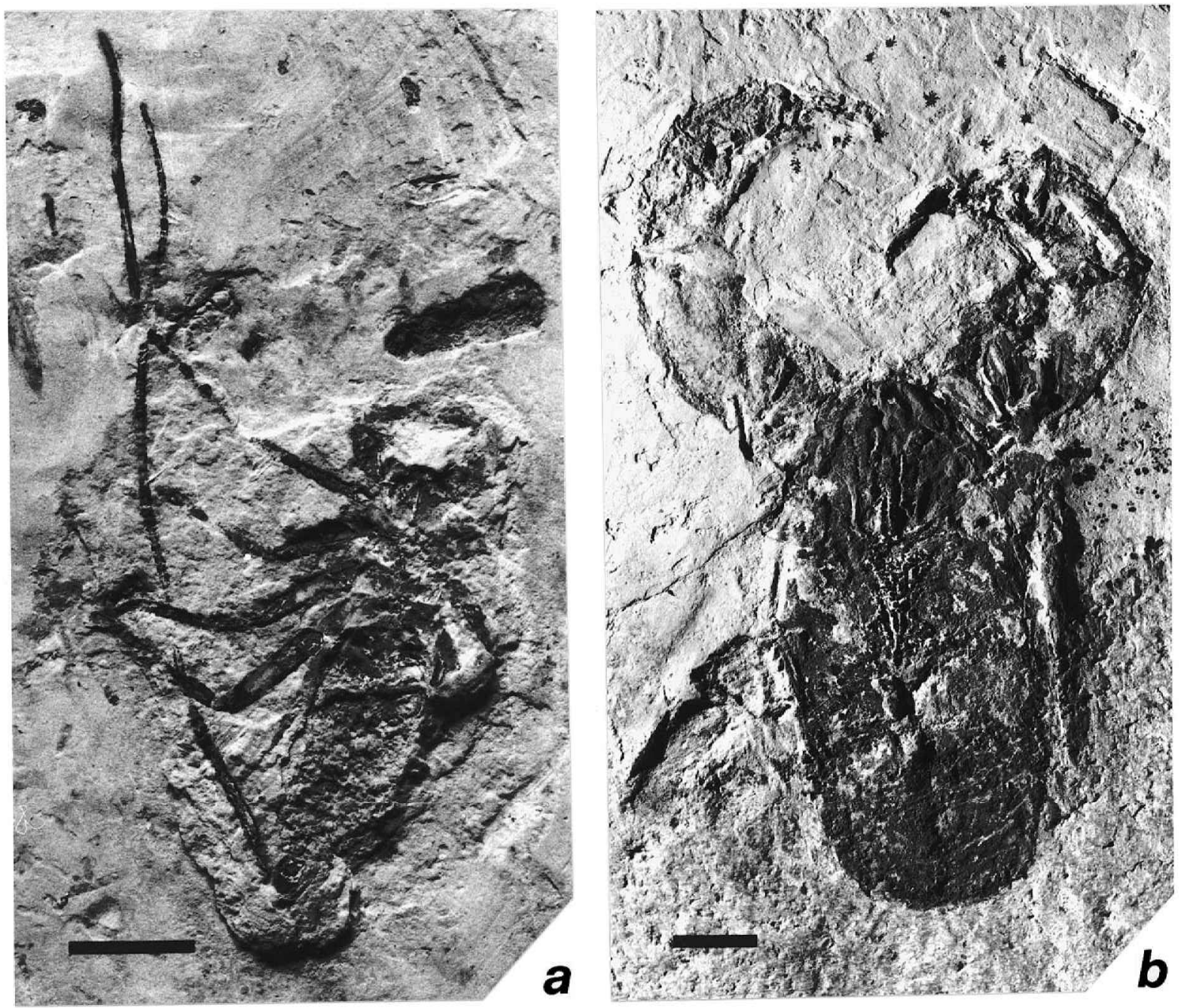

Figure 3 (a) Mesoproctus rowlandi Dunlop, 1988. SMNS 64331; a less well-preserved example of this whipscorpion; this fossil has less robust pedipalps and shorter segments comprising the flagellum (compare Figs $2 \mathrm{~b}$ and 4a); (b) Mesoproctus sp. MS.A. 1041; an incomplete, but very large prosoma of a whipscorpion (note scale bar) in dorsal view. Both from the Lower Cretaceous (Aptian) Crato Formation of Brazil; scale bars represent $5 \mathrm{~mm}$.

cannot assume that it must belong to an extant group and in the absence of unequivocal morphological data we prefer to leave its familial position open.

\section{Genus Britopygus gen. nov.}

Diagnosis. Cretaceous amblypygid with possible apophysis on pedipalpal trochanter and at least one large femoral spine and two large patella spines on the pedipalp. [Diagnosis is insufficient for a full comparison with extant genera and relies, in part, on the Cretaceous age of the material.]

Derivation of name. In honour of Dr Igancio Machado Brito, for his contribution to Brazilian Cretaceous stratigraphy, and the suffix pygus derived from the order name Amblypygi.

Type species. (Only included species) Britopygus weygoldti gen. et sp nov.

\section{Britopygus weygoldti gen. et sp. nov.}

(Figs 1a, 2a)

Diagnosis. As for the genus.

Derivation of name. In honour of Professor Peter Weygoldt (Albert-Ludwigs-Universität, Freiburg) for his studies on the systematics and biology of extant whipspiders.
Holotype. SMNS 64332. From the Nova Olinda Member, Crato Formation, near Nova Olinda, Ceará State, Brazil. Lower Cretaceous (Aptian).

Description of SMNS 64332. Partially complete prosoma in ventral view primarily showing the proximal podomeres of the appendages (Figs 1a, 2a). Basal podomere of chelicerae subrectangularin outline, length $1 \cdot 1 \mathrm{~mm}$. Cheliceral fangs approximately half the total length of the basal podomere and with a clear median ridge in the distal region. Pedipalpal trochanters short, length a little over $0.5 \mathrm{~mm}$, but boundary between the trochanter and femur poorly preserved. Trochanters with blunt spine-like projection directed anteriorly; possibly the ventral apophysis (see 2.1.). Pedipalpal femora short, length $1.4 \mathrm{~mm}$, squat and rounded distally. At least one large femoral spine present on the left pedipalp. Patella of pedipalp robust, length at least $2.2 \mathrm{~mm}$, but distal region and patella-tibia articulation not clearly preserved. Patella bears at least two large and probably two small spines, possibly mounted on a projecting flange (see 2.1). Distal podomeres of the pedipalps not preserved. Antenniform leg I not preserved, but legs IIIV partially complete. Lengths of femora: II, $3.9 \mathrm{~mm}$; III, $4.4 \mathrm{~mm}$; IV, $4.0 \mathrm{~mm}$. Leg coxae subtriangular, widening distally. Trochanters bell-shaped, widening distally. All femora are narrowest midway along their length and show traces of 

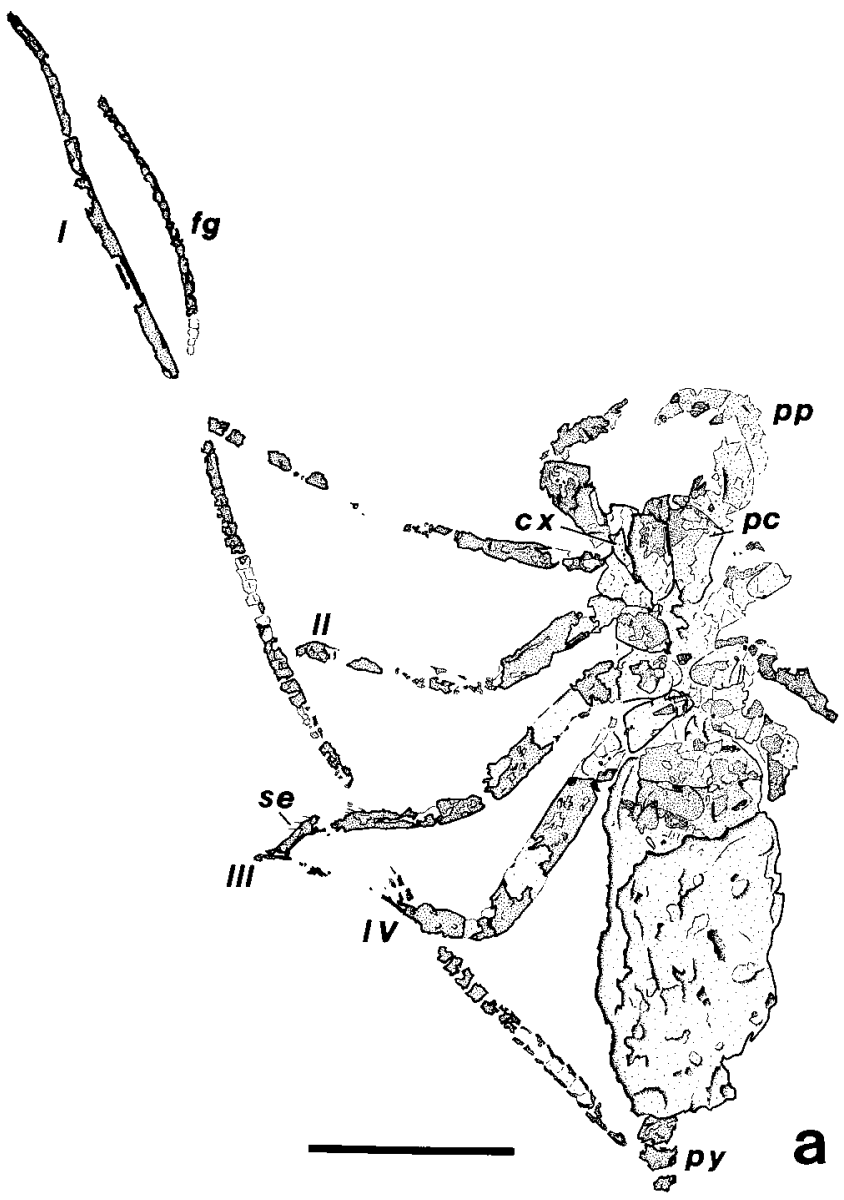

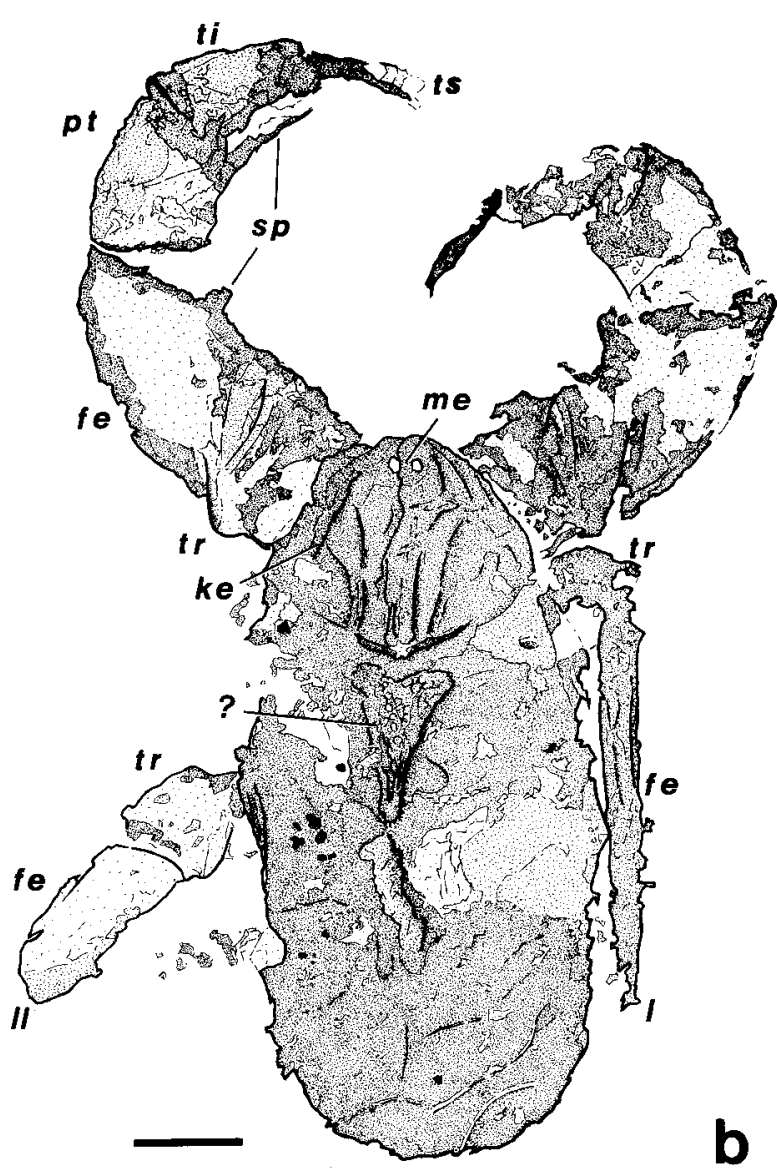

Figure 4 Camera lucida drawing of the specimens shown in Figure 3: (a) Mesoproctus rowlandi Dunlop, 1988; (b) Mesoproctus sp; scale bars represent $5 \mathrm{~mm}$.

longitudinal lineations. Femora II and III with a slight prolateral curvature. Details of sternal region between the leg coxae not clearly preserved. Opisthosoma not preserved.

\section{Order THELYPHONIDA Cambridge, 1872 Family uncertain}

Remarks. Although living representatives of this group were divided into two families by Rowland \& Cooke (1973), this proposal has not been followed by subsequent authors (e.g. Weygoldt 1988; Haupt \& Song 1996) who generally recognise a single family, Thelyphonidae. In his original description of the Cretaceous whipscorpion, Dunlop (1998) was reluctant to refer his fossil to a higher thelyphonid taxon since the presence or absence of keels (a key feature in Rowland \& Cooke's scheme) cannot be determined in the holotype. The large Mesoproctus $\mathrm{sp}$. material described below shows the dorsal carapace which appears to preserve a keel (see below). However, the carapace is not preserved in the other Crato Formation whipscorpions and because of this uncertainty, and the risk of circular reasoning depending on whether all three fossils described here are conspecific, we prefer not to assign them to a family.

\section{Genus Mesoproctus Dunlop, 1998}

Type species. (Only included species) Mesoproctus rowlandi Dunlop, 1998.
Mesoproctus rowlandi Dunlop, 1998

(Figs 1b, 2b, 3a, 4a)

1998 Mesoproctus rowlandi Dunlop, p. 294, figs 1-2.

Material. Holotype: Ulster Museum, Belfast, No. K28006. From the Nova Olinda Member, Crato Formation, near Nova Olinda, Ceará State, Brazil. Lower Cretaceous (Aptian); described by Dunlop (1998). MB.A. 975 (described below). SMNS 64331 (described below). Both from the same region as the holotype, but precise localities unknown.

Description of MB.A 975. Almost complete specimen (Figs $1 b, 2 b$ ) primarily in ventral view, total length (excluding flagellum) $17 \cdot 1 \mathrm{~mm}$. Pedipalps and their coxae massive, the latter with median endites. Coxa of leg I small and preserved on left side only. Coxae of subsequent legs (II-IV) subtriangular, large and robust, surrounding the 'Y-shaped anterior sternum. Left/right position of legs refers to the fossil as preserved in ventral view. Left leg I partially complete, slender, probably consisting of the patella and tibia. Right leg I poorly preserved, folded backwards and in a plane beneath the succeeding legs. Trochanter and only part of femur preserved. Other legs (II-IV) almost complete, especially on right side, with total lengths (excluding coxae) of $8.2 \mathrm{~mm}, 8.5 \mathrm{~mm}$ and $10.7 \mathrm{~mm}$, respectively. Legs II-IV with somewhat bell-shaped trochanter, robust femur, distally widening patella and slender tibia, basitarsus and tarsus. Left leg II partially complete. Right leg II almost complete, with probable pair of small claws or 


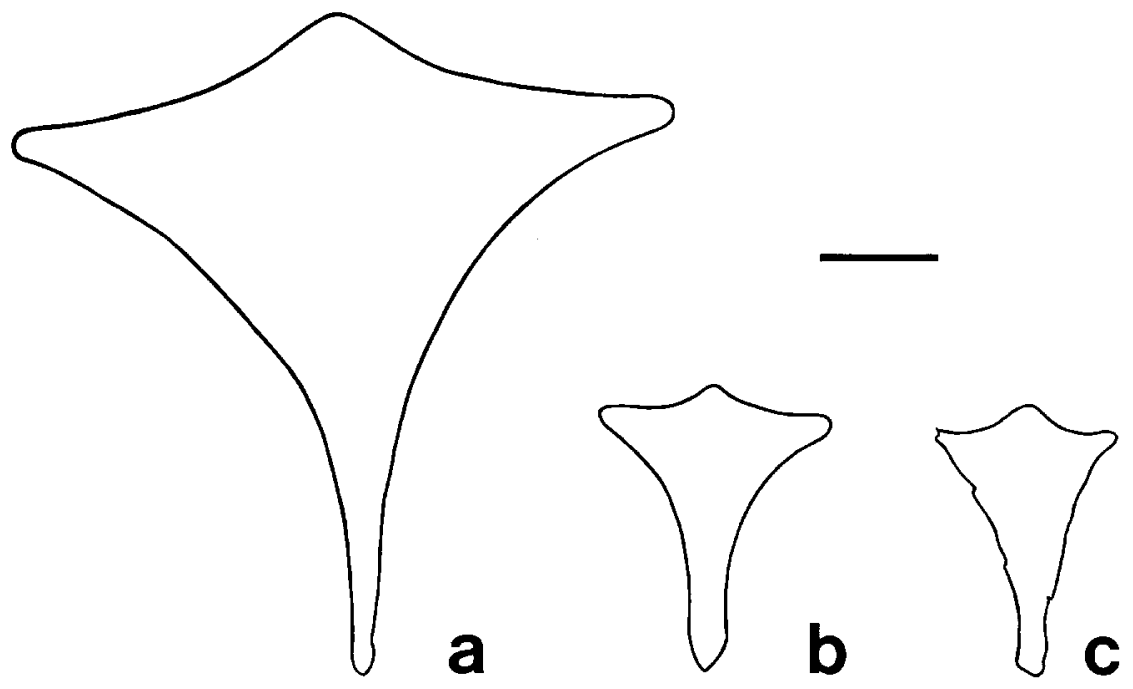

Figure 5 Camera lucida sketches of the anterior sternum in an adult (a) and juvenile (b) of the extant whipscorpion Mastigoproctus giganteus; the anterior sternum of the fossil specimen (c) of Mesoproctus rowlandi (MB.A. 975) is closer to the juvenile morphology in lacking the pronounced elongation of the two anterior corners and the posterior end of the sternum; MB.A. 975 may therefore be a subadult whipscorpion; all drawings to scale; scale bar represents $1 \mathrm{~mm}$.

ungules distally. Left leg III partially complete. Right leg III almost complete with a clear, unequivocal pair of distal claws. Left leg IV rather poor. Distal end of leg IV poorly preserved. Opisthosoma elongate, length approximately $12 \mathrm{~mm}$, width $3.5 \mathrm{~mm}$. Posterior end of opisthosoma forms a pygidium, length $1.6 \mathrm{~mm}$, composed of poorly defined, ring-like segments which are bent slightly to the right. Flagellum almost complete, length $15.5 \mathrm{~mm}$, originating from the pygidium and curving dextrally. At least 18 individual articles can be distinguished, all longer than wide, but these become less well-defined distally.

Description of SMNS 64331. Almost complete, but less wellpreserved specimen, also in ventral view (Figs 3a, 4a). Total length (exlcuding flagellum) $16 \cdot 8 \mathrm{~mm}$. Pedipalpal coxae large, but pedipalps incomplete and lacking details. Legs partially complete on left side, but almost entirely lacking on right side. Leg I longest, characteristically slender and elongate. Length $c .20 \mathrm{~mm}$, but individual podomeres poorly preserved midway along its length. Legs II-IV shorter and thicker. Leg III with podomere lengths: trochanter $1.0 \mathrm{~mm}$, femur $3.3 \mathrm{~mm}$, patella $1.3 \mathrm{~mm}$, tibia $2.5 \mathrm{~mm}$. Details of tarsus not preserved. Opisthosoma rather poorly preserved, elongate in outline, length $9.0 \mathrm{~mm}$, width $4.2 \mathrm{~mm}$, but with the exception of two darker areas anteriorly, little of the original segmentation remains. The bulk of the opisthosoma is pale and featureless. Posteriorly, three pygidial segments can be distinguished, total length of pygidium $1.8 \mathrm{~mm}$. Flagellum well preserved, length $28.0 \mathrm{~mm}$, comprising at least 70 individual articles.

Remarks. Two distinct morphological differences between MB.A. 975 and SMNS 64331 can be identified: the latter specimen has less robust pedipalps and the flagellum is longer and composed of shorter, broader articles (compare Figs $1 \mathrm{~b}$ and 2a). Both characters could be interpreted as species-specific features, but we are reluctant to create a new taxon on the grounds that total number of whipscorpion specimens described from the Crato Formation (four) does not allow a sensible appraisal of intra-specific morphological diversity, and since comparisons with extant whipscorpions cast doubt on the taxonomic value of both the features noted above. The pedipalps of numerous species extant whipscorpion have been shown to be sexually dimorphic, with males having slightly larger appendages (e.g. Weygoldt 1971, 1978) which they use to grab the female during mating. The pedipalps of SMNS 64331 are not particularly well preserved and in the absence of better evidence we regard this possibly secondary sexual character as unreliable. The flagella of the two whipscorpions described here are clearly different. However, examination of numerous specimens of the extant species Thelyphonus caudatus and Typopeltis crucifer suggests that the length of the telson is wholly unreliable as a character (it is prone to breaking at various points along its length) and that the proportions of individual articles within the flagellum can vary intraspecifically and even within an individual. We are therefore reluctant to create a new taxon based on differences in the detailed morphology of the flagellum. In the absence of convincing morphological differences between the new fossils and the holotype of $M$. rowlandi, we regard all three small fossil whipscorpions from the Crato Formation as conspecific.

\section{Mesoproctus sp. \\ (Figs 3b, 4b)}

Material. MB.A. 1041. From the Nova Olinda Member, Crato Formation, near Nova Olinda, Ceará State, Brazil. Lower Cretaceous (Aptian). Collected by DMM.

Description of MB.A. 1041. Partially complete prosoma in dorsal view (Figs 3b, 4b). Carapace almost complete, elongate, tapering anteriorly in the anterior third and slightly rounded posteriorly. Length $32.5 \mathrm{~mm}$, width $16.0 \mathrm{~mm}$. Carapace with paired median eyes close to anterior border. Lateral eyes not preserved, but apparent ridge or intraocular keel runs on left side of carapace between the median eyes and the expected position of the lateral eye tubercle. Pedipalps complete, length approximately $32 \mathrm{~mm}$, robust and semiraptorial. Palpal trochanters rather poorly preserved, lacking the spinous anterior margin seen in extant taxa. Palpal femora with small thorn-like projection on meso-distal edge. Apophysis of patella preserved on left pedipalp, but individual dactyli of the tibiatarsus claw complex are not preserved. Proximal podomeres of leg I preserved on right side. Trochanter rounded, length $3.0 \mathrm{~mm}$. Femur narrow and elongate, maximum preserved length $19 \cdot 0 \mathrm{~mm}$. Proximal podomeres of leg II preserved on left side. Trochanter bulbous, length $5.0 \mathrm{~mm}$ with distal 
flange. Femur incomplete, but robust with maximum preserved length $9.5 \mathrm{~mm}$. Additional appendages absent.

Remarks. The comparatively large size of this fossil might indicate that it is a new species, different from $M$. rowlandi. However, size is an unreliable species character, especially when only a handful of fossil whipscorpions are known from this locality, with evidence that at least one of them might be a juvenile (see 2.3). Thus MB.A. 1041 could conceivably be an adult of $M$. rowlandi, but since the material is incomplete this cannot be tested and we prefer not to assign it to a species pending further data.

\section{Acknowledgements}

We thank Günter Bechly (SMNS) and Erika Pietrzeniuk (MB.A.) for the loan of material in their care. Vera Heinrich (Berlin) prepared the photographs. We especially thank Peter Weygoldt for comments on extant whipspiders, J. Mark Rowland, Justin O. Schmidt and Joachim Haupt for comments on extant whipscorpions and an anonymous reviewer for suggesting improvements to the manuscript. Mark Harvey kindly advised us on potential homonyms. DMM thanks Artur Andrade (D. N. P. M. Crato) and Dr Paulo Brito for help with field work in Brazil. DMM is supported by NERC grant GR9/02503.

\section{References}

Brauckmann, C. \& Koch, L. 1983. Prothelyphonus naufragus n. sp., ein neuer Geißelskorpion (Arachnida: Thelyphonida: Thelyphonidae) aus dem Namurium (unteres Ober-Karbon) von WestDeutschland. Entomologische Generalis 9, 63-73.

Cambridge, O. P. 1872. On a new family and genus and two new species of Thelyphonida. Annals and Magazine of Natural History, Series 4 10, 409-13.

Campos, D. R. B. 1986. Primeiro registro fossil de Scorpionidae na chapada do Araripe (Cretaceo Inferior), Brasil. Anais da Academia Brasileira de Ciências 58(1), 135-7.

Campos, D. R. B., Costa, A. T. \& Martins-Neto, R. G. 1988. Araneida fóssil do Cretáceo Inferior da Bacia do Araripe. Anais da Academia Brasileira de Ciências 60(4), 494.

Davis, S. \& Martill, D. M. 1999. The gonorynchiform fish Dastilbe from the Lower Cretaceous of Brazil. Palaeontology 42, 715-40.

Dunlop, J. A. 1998. A fossil whipscorpion from the Lower Cretaceous of Brazil. The Journal of Arachnology 26, 291-5.

Dunlop, J. A. \& Horrocks, C. 1996. A new Upper Carboniferous whip scorpion (Arachnida: Uropygi: Thelyphonida) with a revision of the British Carboniferous Uropygi. Zoologischer Anzeiger 234, 293-306.

Grimaldi, D. 1990. Insects from the Santana Formation, Lower Cretaceous, of Brazil. Bulletin of the American Museum of Natural History 195, 5-191.

Haupt, J. \& Song, D. 1996. Revision of East Asian whip scorpions (Arachnida Uropygi Thelyphonida). I. China and Japan. Arthropoda Selecta $\mathbf{3 / 4}, 43-52$

Lucas, H. 1835. Essai sur une Monographie du genere Thelyphone in Magas. de Zool. de M. Guérin 1835. CI. VII, Tfl. VIII.

Maisey, J. G. 1990. Stratigraphy and depositional environment of the Crato Member (Santana Formation, Lower Cretaceous) of northeast Brazil. 15-19. In Grimaldi, D. A. (ed.). Insects from the Santana Formation, Lower Cretaceous, of Brazil. Bulletin of the American Museum of Natural History. 195, 5-191.

Maisey, J. G.1991. Santana fossils: an illustrated atlas. New Jersey, USA: T.F.H. Publications.

Martill, D. M. 1993. Fossils of the Santana and Crato Formations, Brazil. The Palaeontological Association Field Guides to Fossils 5, $1-159$.
Martill, D. M. \& Davis, P. G. 1998. Did dinosaurs come up to scratch? Nature 396, 528-9.

Martill, D. M. \& Filgueira, J. B. M. 1994. A new feather from the Lower Cretaceous of Brazil. Palaeontology 37, 483-7.

Martill, D. M. \& Frey, E. 1995. Colour patterning preserved in Lower Cretaceous birds and insects: the Crato Formation of N.E. Brazil. Neues Jahrbuch für Geologie und Paläontologie, Monasthefte 1995, $118-28$.

Martill, D. M. \& Frey, E. 1998. A new pterosaur Lagerstätte in N. E. Brazil (Crato formation, Aptian, Lower Cretaceous): preliminary observations. Oryctos 1, 79-85.

Mello-Leitao, C. de 1931. Pedipalpos do Brasil, e algumas notas sobre a ordem. Archivos do Museu Nacional 33, 1-71.

Mesquita, M. V. 1996. Cretaraneus martinsnetoi n.sp. (Araneoidea) da Fromacao Santana, Cretáceo inferior da Bacia do Araripe. Revista Universidade Guarulhos - Série Geociencias 1(3), 24-31.

Petrunkevitch, A. I. 1953. Paleozoic and Mesozoic Arachnida of Europe. Memoirs of the Geological Society of America 53, 1-122.

Pocock, R. I. 1894. Notes on the Thelyphonidae contained in the collection of the British Museum. Annals and Magazine of Natural History, Series 6 14, 120-34.

Pons, D., Berthou, P.-Y.\& Campos, D. A. 1990. Quelques observations sur la palynologie de l'Aptien superieur et de l'Albien du Bassin d'Araripe, In Campos, D. R. B., Viana, M. S. S., Brito, P. M. \& Beurlen, G. (eds). Atas do simposio sobre a Bacia do Araripe e Bacias Interiores do Nordeste, Crato, 14-16 de Junho de 1990, 241-52. Crato, $405 \mathrm{pp}$.

Rowland, J. M. \& Cooke, J. A. L. 1973. Systematics of the arachnid order Uropygida (= Thelyphonida). The Journal of Arachnology, $1,55-71$.

Schwaller, W. 1982. Neue Befunde an Geißelspinnen in Dominikanischem Bernstein (Stuttgarter Bernsteinsammlung: Arachnida, Amblypygi). Stuttgarter Beiträge zur Naturkunde Serie B (Geologie und Paläontologie) 86, 1-12.

Selden, P. A. \& Shear, W. A. 1996. The first mesozoic Solifugae (Arachnida), from the Cretaceous of Brazil and a redescription of the Palaeozoic solifuge. Palaeontology 39, 583-604.

Shultz, J. W. 1990. Evolutionary morphology and phylogeny of Arachnida. Cladistics 6, 1-38.

Shultz, J. W. 1993. Muscular anatomy of the giant whipscorpion Mastigoproctus giganteus (Lucas) (Arachnida: Uropygi) and its evolutionary significance. Zoological Journal of the Linnean Society 108, 335-65.

Shultz, J. W. 1999. Muscular anatomy of a whipspider, Phrynus longipes (Pocock) (Arachnida, Amblypygi), and its evolutionary significance. Zoological Journal of the Linnean Society 126, 81-116.

Tarnani, J. 1889. Sur les Collections des Thelyphonides de quelques Musées russes. Zoologischer Anzeiger 301, 118-22.

Thorell, T. 1883. Descrizione di alcuni Aracnidi inferiori dell'arcipelago Malese. Annali del Museo Civico di Storia Naturale di Genova 18, $21-69$.

Weygoldt, P. 1971. Notes on the life history and reproductive biology of the giant whip scorpion, Mastigoproctus giganteus (Uropygi, Thelyphonidae) from Florida. Journal of Zoology, London 164, $137-47$

Weygoldt, P. 1972. Charontidae (Amblypygi) aus Brasilien. Zoologische Jahrbücher, Abteilung für Systematik, Ökologie und Geographie der Tiere 99, 107-32.

Weygoldt, P. 1978. Paarungsverhalten und Spermatophorenmorphologie bei Geißelskorpionen: Thelyphonellus amazonicus Butler und Typopeltis crucifer Pocock (Arachnida, Uropygi). Zoomorphologie 89, 145-56.

Weygoldt, P. 1988. Sperm transfer and spermatophore morphology in the whip scorpion Thelyphonus linganus (Arachnida: Uropygi: Thelyphonidae). Journal of Zoology, London 215, 189-96.

Weygoldt, P. 1995. The development of the phrynichid 'hand': notes on allometric growth and introduction of the new generic name Euphrynichus (Arachnida, Amblypygi). Zoologischer Anzeiger 234, 75-84.

Weygoldt, P. 1996. Evolutionary morphology of whip spiders: towards a phylogenetic system (Chelicerata: Arachnida: Arnblypygi). Journal of Zoological, Systematic and Evolutionary Research, 34, 185202.

Weygoldt, P. 2000. Whip Spiders (Chelicerata. Amblypygi). Their Biology, Morphology and Systematics. Stenstrup: Apollo Books.

Yoshikura, M. 1965. Postembryonic development of a whip-scorpion Typopeltis stimpsonii (Wood). Kummamoto Journal of Science, Series $B, 7(2), 21-50$ 
JASON A. DUNLOP, Institut für Systematische Zoologie, Museum für Naturkunde der Humboldt-Universität zu Berlin, D-10115 Berlin, Germany.

E-mail: jason.dunlop@rz.hu-berlin.de

DAVID M. MARTILL, School of Earth, Environmental and Physical Sciences, Burnaby Building, University of Portsmouth, Portsmouth, PO1 3QL, UK.

E-mail: david.martill@port.ac.uk

MS received 7 June 2000. Accepted for publication 29 January 2001. 